\title{
Impact of hypoglycemia on patients with type 2 diabetes mellitus and their quality of life, work productivity, and medication adherence
}

This article was published in the following Dove Press journal:

Patient Preference and Adherence

8 May 2014

Number of times this article has been viewed

Janice MS Lopez'

Kathy Annunziata ${ }^{2}$

Robert A Bailey'

Marcia FT Rupnow'

Donald E Morisky ${ }^{3}$

'Janssen Scientific Affairs, LLC, Raritan, NJ, ${ }^{2}$ Kantar Health, Princeton, NJ, ${ }^{3}$ University of California at Los Angeles Fielding School of Public Health, Los Angeles, CA, USA
Correspondence: Janice MS Lopez Janssen Scientific Affairs, LLC, 1000 Route 202 South, Raritan, NJ 08869, USA

Tel +l 4I0465 5508

Fax +I 4104655538

Email jmlopez@its.jnj.com
Background: The purpose of this study was to determine the characteristics of adults with type 2 diabetes mellitus (T2DM) that correlate with greater risk of hypoglycemia and determine the impact of hypoglycemia on health-related quality of life, work productivity, and medication adherence from a patient perspective.

Methods: Data from a large web-based survey were retrospectively analyzed. Adults with a diagnosis of T2DM taking antihyperglycemic agents were included in the analysis. Participants with knowledge of their hypoglycemic history were divided into three groups: those experiencing recent hypoglycemia (previous 3 months), those experiencing nonrecent hypoglycemia, and those never experiencing hypoglycemia.

Results: Of the participants with T2DM taking antihyperglycemic agents who were knowledgeable of their hypoglycemia history, 55.7\% had ever experienced hypoglycemia. Of those, $52.7 \%$ had recent hypoglycemia. Compared with those who never experienced hypoglycemia, those who experienced hypoglycemia tended to: be younger; be more aware of their glycated hemoglobin $\left(\mathrm{HbA}_{1 \mathrm{c}}\right)$ levels; have higher $\mathrm{HbA}_{1 \mathrm{c}}$ levels; have a higher body mass index; have higher Charlson Comorbidity Index scores; be on insulin, sulfonylureas, and/or glucagon-like peptide-1 agonists; and be less adherent to their antihyperglycemic agents. Hypoglycemia interfered with social activities, caused more missed work (absenteeism), more impairment while at work (presenteeism), and decreased overall work productivity compared with patients who had never experienced hypoglycemia. Overall health-related quality of life, as determined by the Short Form-36 health questionnaire, was negatively impacted by hypoglycemia. Both Physical and Mental Summary scores were significantly lower for the recent hypoglycemia and nonrecent hypoglycemia groups compared with the never hypoglycemia group.

Conclusion: Hypoglycemia can negatively impact many aspects of life. Greater awareness of those who are at risk for developing hypoglycemia can lead to the development of measures (eg, patient and physician education) to prevent future hypoglycemia episodes.

Keywords: adherence, survey, patient preference, burden, antihyperglycemic, low glucose effect, hemoglobin $\mathrm{A}_{1 \mathrm{C}}$

\section{Introduction}

Several large-scale, prospective, randomized trials have documented that lowering glycemic levels can prevent the development of microvascular disease in people with type 2 diabetes mellitus (T2DM). Consequently, T2DM management guidelines generally recommend a treatment target of glycated hemoglobin $\left(\mathrm{HbA}_{\mathrm{lc}}\right)$ levels $<7.0 \%$, with some suggesting that even more intensive glycemic goals $(<6.5 \%)$ would be beneficial. ${ }^{1-3}$ However, one issue with intensive glycemic control is the possibility of hypoglycemic events. 
Treatment-related hypoglycemia is known to occur in people with T2DM, but its impact from the individual patient's perspective is not well characterized. Determining the impact of hypoglycemia on the lives of people with T2DM is very difficult since there is no consensus definition of hypoglycemia. This results in inconsistencies in the identification, measurement, and reporting methods across studies. The incidence and impact of hypoglycemia can be masked by factors such as age, treatment modality, duration of diabetes, body weight, and glycemic control. ${ }^{4}$ The acute and chronic complications of hypoglycemia invariably affect various aspects of life, including work productivity, social interactions, sleep, sexual activity, driving, sport and leisure activities, and adherence to therapy. ${ }^{5,6}$ Acute symptoms can be mild (eg, palpitations, tremor, hunger, sweating) or severe (eg, behavioral changes, difficulty thinking, confusion, loss of consciousness). Long-term complications of hypoglycemia include cardiovascular and neurological complications, such as myocardial infarction, arrhythmias, stroke, cognitive decline, dementia, and cardiovascular death. ${ }^{4,7}$ Healthrelated quality of life (HRQoL) may be affected as a result of the complications and/or effects of hypoglycemia, or as a consequence of avoidant, precautionary, or compensatory actions due to the fear of having a hypoglycemia episode. ${ }^{4}$ Glycemic control may be an issue since patients who experience hypoglycemia are more prone to worry about future hypoglycemic events and may maintain higher glycemic levels to avoid hypoglycemia. ${ }^{5,8}$ Glycemic control may also suffer if health care providers delay advancement of treatment due to similar fears. ${ }^{9}$ The result is a negative impact on overall HRQoL, which has been well documented in studies on hypoglycemia in people with T2DM.,7

There are data to suggest that hypoglycemia can have a significant impact on many aspects of the lives of people with T2DM. However, there have not been any previous studies on the characterizations and impacts of hypoglycemia on HRQoL, work productivity, and medication adherence in people with T2DM purely based on the patient perspective and in a single analysis. In addition, the impact of hypoglycemia on these factors in association with glycemic control and burden of disease within the same study has not been examined. Consequently, the purpose of this study is to retrospectively analyze a large sample of people with T2DM to describe their perspectives on the impact of hypoglycemia on diabetes and related comorbidity burden, HRQoL, and work productivity, as well as the association between hypoglycemia and adherence to antihyperglycemic medication.

\section{Materials and methods}

\section{Survey design}

The US National Health and Wellness Survey (NHWS) is a cross-sectional, Internet-based survey of adults aged $\geq 18$ years. Using a stratified random sampling framework, potential respondents are recruited through Internet panels such that the demographic composition of the NHWS is identical to that of the general population, as measured by the US Census. The reliability and validity of the NHWS, particularly as it relates to disease prevalence, has been assessed in prior research. ${ }^{10-12}$ These studies have compared data collected from the NHWS and various other sources, including the US Census Bureau's Current Population Survey, National Health Interview Survey, National Health and Nutrition Examination Survey, and the Medical Expenditure Panel Survey. ${ }^{10-12}$

Data from the 2012 NHWS were analyzed for this descriptive analysis. The NHWS was administered to a sample of adults who were identified through a web-based consumer panel. It is a cross-sectional, self-administered, web-based survey encompassing 100 various conditions. The diabetes condition series consists of 41 questions. Survey data for this analysis were collected during the first three quarters of 2012. The projected number of US adults diagnosed with diabetes from the NHWS aligned favorably with the estimate from the National Health Interview Survey results and is thus nationally representative. ${ }^{13}$

\section{Participant selection}

Participants were recruited through opt-in emails, coregistration with other panels, e-newsletter campaigns, and online banner placements. The total sample size of the NHWS consisted of 71,157 participants. Participants were included in this analysis if they were adults aged 18 years or older who reported a diagnosis of T2DM. At the time of the survey, participants self-identified as taking prescription antihyperglycemic agent(s) to treat diabetes.

\section{Participant characterization}

Hypoglycemia was identified by self-report by participants in response to questions in the survey. Participants were asked if they had ever experienced hypoglycemia or low blood sugar as a result of their diabetes, with examples of symptoms of hypoglycemia provided (shakiness, nervousness, sweating, dizziness-lightheadedness, sleepiness, confusion, difficulty speaking, anxiety, weakness, fainting, crying out or having nightmares, finding clothes or sheets damp from perspiration, feeling tired, irritable, or confused after waking up). 
Participants were grouped into one of three potential hypoglycemia categories: those who had experienced hypoglycemia within the previous 3 months (recent hypoglycemia); those who had experienced hypoglycemia in the past, but not in the previous 3 months (nonrecent hypoglycemia); and those who had never experienced hypoglycemia (never hypoglycemia).

Race/ethnicity, degree of blood glucose control, body mass index (BMI), Charlson Comorbidity Index (CCI) scores, medication adherence, health-related HRQoL, and work productivity were determined for each hypoglycemia category. For race/ethnicity, five categories were reported, ie, White, African American, Hispanic, Asian, and American Indian. Participants with more than one race/ethnicity or who did not belong to one of the five main categories were excluded from this analysis. For the degree of blood glucose control, participants self-reported their most recent $\mathrm{HbA}_{1 \mathrm{c}}$ level by responding to the question, "What is your hemoglobin $A_{1 c}$ level?" They were then categorized into one of five categories: low $(<7.0 \%)$, slightly elevated ( $\geq 7.0 \%$ to $\leq 8.5 \%$ ), elevated $(>8.5 \%$ to $\leq 11.0 \%$ ), seriously elevated $(>11.0 \%)$, and those who did not know their $\mathrm{HbA}_{1 \mathrm{c}}$ levels. BMI was calculated based on self-reported height and weight, then categorized into one of four categories: obese ( $\geq 30 \mathrm{~kg} / \mathrm{m}^{2}$ ), overweight ( 25 to $<30 \mathrm{~kg} / \mathrm{m}^{2}$ ), normal weight ( $\geq 19$ to $<25 \mathrm{~kg} / \mathrm{m}^{2}$ ), and underweight $\left(<19 \mathrm{~kg} / \mathrm{m}^{2}\right)$. Mortality risk based on self-reported comorbid conditions was calculated using the CCI as another indicator of disease burden. Increasing CCI score has been shown to correlate with increased risk of mortality in people with T2DM. ${ }^{14,15}$ In order to remain true to the method of identifying all conditions and diseases, diabetes remained a condition measured in the CCI and counted for one point.

\section{Adherence characterization}

Adherence to antidiabetic medications was determined using the Morisky Medication Adherence Scale (MMAS). The MMAS is a structured, self-reported measure with higher scores representing higher medication adherence. The English version of the eight-item MMAS (MMAS-8) has not been validated in patients with T2DM, but has been validated in hypertensive patients taking antihypertensive medications. ${ }^{16}$ The Malaysian version of the MMAS- 8 and the four-item MMAS (MMAS-4) have been validated in patients with T2DM. ${ }^{17}$ The MMAS- 8 has been assessed for its reliability and congruence with the MMAS-4 in T2DM patients taking antidiabetic medications which has shown that increased scores in the MMAS-4 are significantly associated with decreasing $\mathrm{HbA}_{1 \mathrm{c}}$ levels. ${ }^{17-20}$ In this analysis, the eight-item questionnaire was truncated to seven items, eliminating the question "Do you sometimes forget to take your pills?" The question was removed to prevent confusion for those participants on insulin and other injectable medications in order to preserve their inclusion in the study. From a reliability assessment, the developer of the scale assessed the internal consistency of the seven-item scale and it did not significantly differ for reliability; removing the question decreases the internal consistency (Cronbach's $\alpha$ ) of the MMAS- 8 from 0.83 to $0.78 .{ }^{16}$ A MMAS score of 7 is categorized as high adherence, 5-6 is medium adherence, and $<5$ is low adherence.

\section{Health-related quality of life}

Quality of life was determined using the Short Form-36 health survey (SF-36), version $2,{ }^{21}$ and specific questions from the NHWS (eg, interference with normal social activities due to physical health or emotional problems, whether patients feel hassled about taking their antihyperglycemic medications, whether the participant had symptoms that required assistance from a health care practitioner). Physical and mental summary scores were derived based on scores from the eight domains of the SF-36 (physical functioning, role-physical, bodily pain, general health perceptions, vitality, social functioning, role-emotional, and mental health).

\section{Work productivity}

Work productivity was determined by absenteeism and presenteeism based on self-reported days/hours missed from work. Absenteeism is defined as the percentage of work time missed due to hypoglycemia-related health issues. Presenteeism is defined as the percentage of overall work impaired by hypoglycemia-related health issues. Overall work productivity impairment is defined as the percentage of time missed due to either absenteeism or presenteeism.

\section{Statistical analysis}

Statistical analyses were conducted with IBM SPSS Data Collection Quantum Version 5.8.1 (IBM Corp, Armonk, NY, USA). Group comparisons were performed using unpaired $t$-tests or analysis of variance for continuous variables and chi-square analysis for categorical variables.

\section{Results}

A total of 7,239 participants reported a diagnosis of T2DM (Table 1). Of those, 6,065 were treated with antihyperglycemic agents (oral and injectable agents). The mean age 
Table I Characteristics of survey participants with T2DM who were treated with antihyperglycemic agents

\begin{tabular}{|c|c|}
\hline & n (\%) \\
\hline Participants reporting a diagnosis of T2DM & 7,239 \\
\hline Treated participants with T2DM & $6,065(100.0)$ \\
\hline \multicolumn{2}{|l|}{ Demographics } \\
\hline Mean age (years $\pm S D$ ) & $60.6 \pm 11.5$ \\
\hline \multicolumn{2}{|l|}{ Sex } \\
\hline Male & $3,655(60.3)$ \\
\hline Female & $2,410(39.7)$ \\
\hline \multicolumn{2}{|l|}{ Race/ethnicity } \\
\hline White & $4,658(76.8)$ \\
\hline African American & $693(11.4)$ \\
\hline Hispanic & $400(6.6)$ \\
\hline Asian & $128(2.1)$ \\
\hline American Indian & $92(1.5)$ \\
\hline \multicolumn{2}{|l|}{ Clinical characteristics } \\
\hline \multicolumn{2}{|l|}{$\mathrm{HbA}_{\mathrm{Ic}}(\%)$} \\
\hline Low $(<7.0 \%)$ & $2,163(35.7)$ \\
\hline Slightly elevated $(\geq 7.0 \%$ and $\leq 8.5 \%)$ & I,299 (21.4) \\
\hline Elevated $(>8.5 \%$ to $\leq \mathrm{II} .0 \%)$ & $247(4.1)$ \\
\hline Seriously elevated (>11.0\%) & $55(0.9)$ \\
\hline Don't know & $2,186(36.0)$ \\
\hline Mean \pm SD & $6.9 \pm 1.3$ \\
\hline Mean BMI $\left(\mathrm{kg} / \mathrm{m}^{2} \pm \mathrm{SD}\right)$ & $33.8 \pm 7.7$ \\
\hline Ever experienced high cholesterol & $3,784(62.4)$ \\
\hline Ever experienced hypertension & $3,867(63.8)$ \\
\hline \multicolumn{2}{|l|}{ Antihyperglycemic agents } \\
\hline Insulin & $\mathrm{I}, 742(28.7)$ \\
\hline Metformin & $3,176(57.3)$ \\
\hline Sulfonylureas & $2,101(37.9)$ \\
\hline DPP-4 inhibitors & $572(10.3)$ \\
\hline GLP-I agonists & $323(5.8)$ \\
\hline Thiazolidinediones & $530(9.6)$ \\
\hline
\end{tabular}

Abbreviations: $\mathrm{HbA}_{1 \mathrm{lc}}$, glycated hemoglobin; $\mathrm{BMI}$, body mass index; DPP-4, dipeptidyl peptidase-4; GLP-I, glucagon-like peptide-I; SD, standard deviation; T2DM, type 2 diabetes mellitus. was 60.6 years and the majority $(60.3 \%)$ was male. A large proportion of participants $(36.0 \%)$ did not know their $\mathrm{HbA}_{1 \mathrm{c}}$ levels. In those who reported $\mathrm{HbA}_{1 \mathrm{c}}$, mean levels were $6.9 \%$. Over $60 \%$ of participants had hypertension and/or high cholesterol.

Of the participants who were treated with antihyperglycemic agents $(n=6,065), 5,756$ (94.9\%) knew their hypoglycemia status (Figure 1). Approximately $56 \%$ of participants who knew their hypoglycemia status had experienced hypoglycemia in the past $(n=3,204)$. Approximately $29 \%$ $(n=1,688)$ of those who knew their hypoglycemia status reported experiencing recent hypoglycemia. Over half (53\%) of the participants with recent hypoglycemia required assistance from another person (data not shown). Of the participants who had recent hypoglycemia and self-managed their episodes, $57 \%$ had hypoglycemia episodes monthly (data not shown). In participants who had recent hypoglycemia and needed assistance from another person, 43\% had episodes 2-6 times a year (data not shown).

Table 2 describes the demographic profile according to hypoglycemia group. Participant mean age ranged from 59.2 years to 61.3 years. The recent hypoglycemia group had a lower proportion of male participants $(55.8 \%)$ compared with the nonrecent hypoglycemia $(59.4 \%, P<0.05)$ and never hypoglycemia $(63.8 \%, P<0.05)$ groups. The race/ethnicity distributions were similar among the hypoglycemia groups.

Table 3 describes the incidence of hypoglycemia according to diabetes-related clinical characteristics. The mean

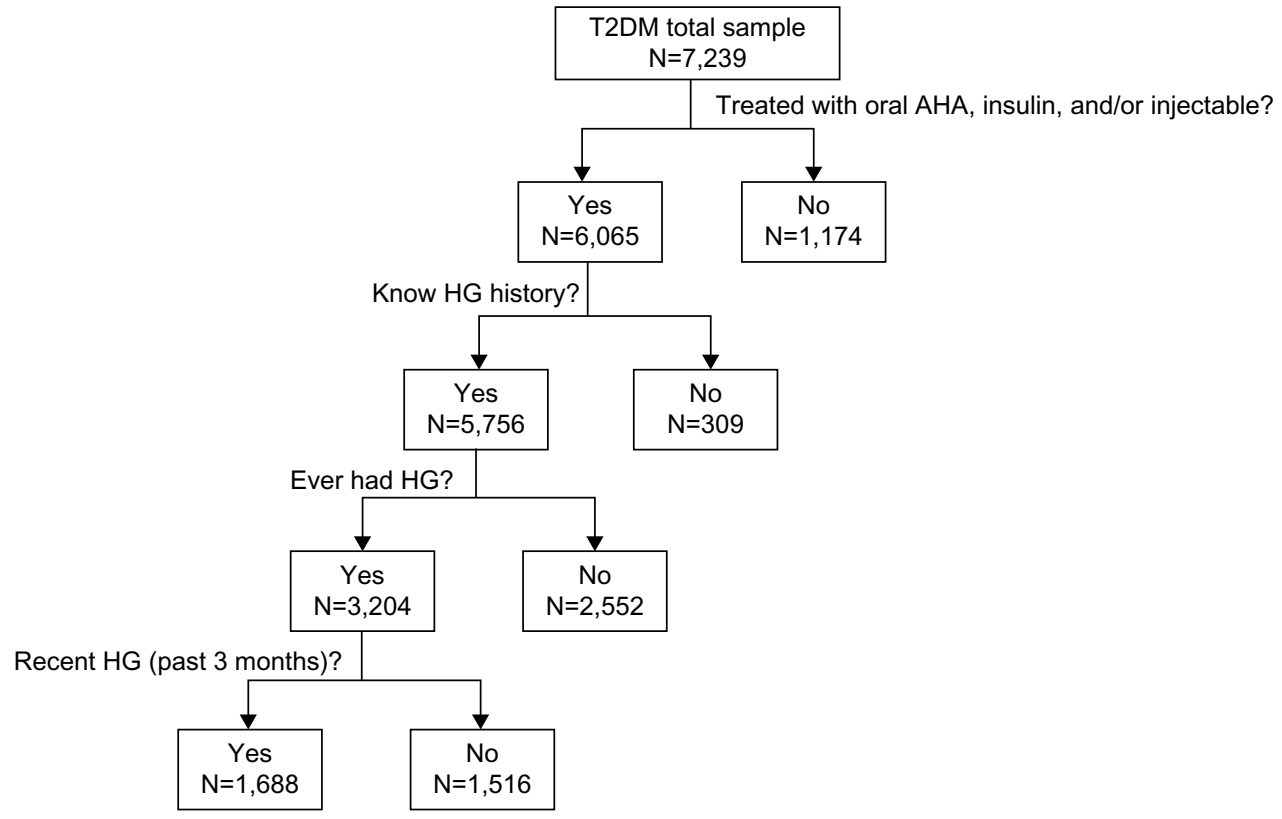

Figure I Description of population.

Abbreviations: HG, hypoglycemia; T2DM, type 2 diabetes mellitus; AHA, antihyperglycemic agent. 
Table 2 Hypoglycemic episodes by demographic profile in participants treated with antihyperglycemic agents

\begin{tabular}{llll}
\hline & $\begin{array}{l}\text { Recent HG } \\
(\mathbf{n}=1,688)\end{array}$ & $\begin{array}{l}\text { Nonrecent HG } \\
(\mathbf{n}=1,516)\end{array}$ & $\begin{array}{l}\text { Never HG } \\
(\mathbf{n}=\mathbf{2 , 5 5 2})\end{array}$ \\
\hline Age, years & & & \\
$18-44$ & $212(12.5 \%)^{\mathrm{a}}$ & $132(8.7 \%)$ & $234(9.2 \%)$ \\
$45-54$ & $324(19.2 \%)^{\mathrm{c}}$ & $271(17.9 \%)$ & $416(16.3 \%)$ \\
$55-64$ & $490(29.0 \%)$ & $444(29.3 \%)$ & $694(27.2 \%)$ \\
$65+$ & $662(39.2 \%)^{\mathrm{a}}$ & $669(44.1 \%)^{\mathrm{c}}$ & $1,208(47.3 \%)$ \\
Mean (years \pm SD) & $59.2 \pm 11.9^{\mathrm{a}}$ & $60.9 \pm 10.9$ & $61.3 \pm 11.5$ \\
Sex & & & \\
Male & $941(55.8 \%)^{\mathrm{a}}$ & $901(59.4 \%)$ & $1,629(63.8 \%)$ \\
Female & $747(44.3 \%)^{\mathrm{a}}$ & $615(40.6 \%)^{\mathrm{c}}$ & $923(36.2 \%)$ \\
Race/ethnicity & & & \\
White & $1,296(76.8 \%)$ & $1,154(76.1 \%)$ & $1,965(77.0 \%)$ \\
African American & $168(10.0 \%)^{\mathrm{b}}$ & $196(12.9 \%)$ & $301(11.8 \%)$ \\
Hispanic & $118(7.0 \%)$ & $104(6.9 \%)$ & $159(6.2 \%)$ \\
Asian & $31(1.8 \%)$ & $22(1.5 \%)^{\mathrm{c}}$ & $67(2.6 \%)$ \\
Native American & $42(2.5 \%)^{\mathrm{a}}$ & $17(\mathrm{I} .1 \%)$ & $28(1.1 \%)$ \\
\hline
\end{tabular}

Notes: $\mathrm{a} P<0.05$ versus both nonrecent $\mathrm{HG}$ and never $\mathrm{HG}$ groups; ${ }^{\mathrm{P}}<0.05$ versus nonrecent $H G$ group only; ${ }^{c} P<0.05$ versus never $H G$ group only.

Abbreviations: HG, hypoglycemia; SD, standard deviation; T2DM, type 2 diabetes mellitus.
$\mathrm{HbA}_{1 \mathrm{c}}$ levels were $7.1 \%$ in the recent hypoglycemia group, $7.0 \%$ in the nonrecent hypoglycemia group, and $6.8 \%$ in the never hypoglycemia group. A larger percentage of participants in the never hypoglycemia group (40.9\%) did not know their $\mathrm{HbA}_{1 \mathrm{c}}$ status compared with the recent hypoglycemia and nonrecent hypoglycemia groups $(27.0 \%$ and $34.3 \%$, respectively, $P<0.05)$. A higher percentage of participants in the recent hypoglycemia group (29.5\%) had slightly elevated $\mathrm{HbA}_{1 \mathrm{c}}$ levels $(\geq 7.0 \%$ to $\leq 8.5 \%$ ) compared with the nonrecent hypoglycemia group $(23.2 \%, P<0.05)$, both of which were significantly higher than the never hypoglycemia group ( $16.5 \%, P<0.05$ for both). Due to the variability between groups in the percentage of participants who did not know or did not report their $\mathrm{HbA}_{1 \mathrm{c}}$ values, glycemic control was also examined only in the participants who reported their $\mathrm{HbA}_{1 \mathrm{c}}$ values (Table 4). In the total population, there were no significant between-group differences in the percentage of participants with low $\mathrm{HbA}_{1 \mathrm{c}}(<7.0 \%)$. However, in those who reported their $\mathrm{HbA}_{1 \mathrm{c}}$ values, a significantly lower percentage

Table 3 Diabetes-related clinical characteristics by hypoglycemia category in participants treated with antihyperglycemic agents

\begin{tabular}{|c|c|c|c|}
\hline n (\%) & $\begin{array}{l}\text { Recent HG } \\
(n=1,688)\end{array}$ & $\begin{array}{l}\text { Nonrecent HG } \\
(n=1,5 \mid 6)\end{array}$ & $\begin{array}{l}\text { Never HG } \\
(n=2,552)\end{array}$ \\
\hline \multicolumn{4}{|l|}{$\mathrm{HbA}_{\mathrm{Ic}}$} \\
\hline Low $(<7.0 \%)$ & $607(36.0 \%)$ & $533(35.2 \%)$ & $933(36.6 \%)$ \\
\hline Slightly elevated ( $\geq 7.0 \%$ to $\leq 8.5 \%$ ) & $498(29.5 \%)^{\mathrm{a}}$ & $35 I(23.2 \%)^{c}$ & $420(16.5 \%)$ \\
\hline Elevated $(>8.5 \%$ to $\leq \mathrm{II} .0 \%)$ & $96(5.7 \%)^{c}$ & $65(4.3 \%)^{c}$ & $78(3.1 \%)$ \\
\hline Seriously elevated (>11.0\%) & $14(0.8 \%)$ & $17(1.1 \%)$ & $21(0.8 \%)$ \\
\hline Do not know & $456(27.0 \%)^{\mathrm{a}}$ & $520(34.3 \%)^{c}$ & I,043 (40.9\%) \\
\hline Mean $(\% \pm S D)$ & $7.1 \pm 1.3^{c}$ & $7.0 \pm 1.3^{c}$ & $6.8 \pm 1.3$ \\
\hline \multicolumn{4}{|l|}{ Antihyperglycemic agents ${ }^{d}$} \\
\hline Insulin & $777(46.0 \%)^{a}$ & $491(32.4 \%)^{c}$ & $433(17.0 \%)$ \\
\hline Metformin & $790(54.8 \%)^{c}$ & $772(56.7 \%)$ & $\mathrm{I}, 436(58.8 \%)$ \\
\hline Sulfonylureas & $674(46.7 \%)^{\mathrm{a}}$ & $582(42.7 \%)^{c}$ & $748(30.6 \%)$ \\
\hline DPP-4 inhibitors & $135(9.4 \%)^{b}$ & $163(12.0 \%)$ & $248(10.2 \%)$ \\
\hline GLP-I agonists & $126(8.7 \%)^{\mathrm{a}}$ & $87(6.4 \%)^{c}$ & $98(4.0 \%)$ \\
\hline Thiazolidinediones & 147 (10.2\%) & $156(11.5 \%)^{c}$ & $206(8.4 \%)$ \\
\hline \multicolumn{4}{|l|}{ BMI $\left(\mathrm{kg} / \mathrm{m}^{2}\right)$} \\
\hline Obese $(\geq 30)$ & I,III $(67.3 \%)^{c}$ & $984(66.7 \%)^{c}$ & $\mathrm{I}, 545(6 \mathrm{I} .9 \%)$ \\
\hline Overweight ( $\geq 25$ to $<30$ ) & $410(24.8 \%)^{c}$ & $375(25.4 \%)^{c}$ & 725 (29.0\%) \\
\hline Normal $(\geq 19$ to $<25)$ & $125(7.6 \%)$ & III (7.5\%) & $223(8.9 \%)$ \\
\hline Underweight $(<19)$ & $5(0.3 \%)$ & $5(0.3 \%)$ & $4(0.2 \%)$ \\
\hline Mean \pm SD & $34.0 \pm 7.7^{c}$ & $34.0 \pm 7.7^{c}$ & $33.3 \pm 7.6$ \\
\hline \multicolumn{4}{|l|}{$\mathrm{CCl}$ score } \\
\hline 1 & $1,004(59.5)^{c}$ & $947(62.5)^{c}$ & $\mathrm{I}, 820(7 \mathrm{I} .3)$ \\
\hline 2 & $317(18.8)^{c}$ & $287(18.9)^{c}$ & $392(15.4)$ \\
\hline 3 & $184(10.9)^{c}$ & $166(11.0)^{c}$ & $219(8.6)$ \\
\hline $4+$ & $183(10.8)^{a}$ & $116(7.7)^{c}$ & $|2|(4.7)$ \\
\hline Mean \pm SD & $1.88 \pm 1.49^{a}$ & $1.72 \pm 1.22^{c}$ & $1.52 \pm 1.05$ \\
\hline
\end{tabular}

Notes: ${ }^{a}<<0.05$ versus both nonrecent $H G$ and never HG groups; ${ }^{b} P<0.05$ versus nonrecent $H G$ group only; ${ }^{c} P<0.05$ versus never $H G$ group only; ${ }^{d}$ antihyperglycemic agents are not mutually exclusive regimens.

Abbreviations: $\mathrm{HbA}_{1}$, glycated hemoglobin; BMI, body mass index; CCl, Charlson Comorbidity Index; DPP-4, dipeptidyl peptidase-4; GLP-I, glucagon-like peptide-I; HG, hypoglycemia; SD, standard deviation; T2DM, type 2 diabetes mellitus. 
Table $4 \mathrm{HbA}_{\mathrm{lc}}$ levels by hypoglycemia category in participants who reported $\mathrm{HbA}_{\mathrm{lc}}$ levels

\begin{tabular}{|c|c|c|c|}
\hline n (\%) & $\begin{array}{l}\text { Recent HG } \\
(n=1,215)\end{array}$ & $\begin{array}{l}\text { Nonrecent HG } \\
(n=966)\end{array}$ & $\begin{array}{l}\text { Never HG } \\
(n=1,452)\end{array}$ \\
\hline Low $(<7.0 \%)$ & $607(50.0 \%)^{\mathrm{a}}$ & $533(55.2 \%)^{b}$ & 933 (64.3\%) \\
\hline $\begin{array}{l}\text { Slightly elevated } \\
\text { ( } \geq 7.0 \% \text { to } \leq 8.5 \%)\end{array}$ & $498(41.0 \%)^{\mathrm{a}}$ & $35 \mathrm{I}(36.3 \%)^{\mathrm{b}}$ & 420 (28.9\%) \\
\hline $\begin{array}{l}\text { Elevated } \\
(>8.5 \% \text { to } \leq 1 \mathrm{I} .0 \%)\end{array}$ & $96(7.9 \%)^{b}$ & 65 (6.7\%) & 78 (5.4\%) \\
\hline $\begin{array}{l}\text { Seriously elevated } \\
(>11.0 \%)\end{array}$ & 14 (I.2\%) & 17 (I.8\%) & 21 (1.5\%) \\
\hline Mean $(\% \pm S D)$ & $7.05 \pm 1.27^{\mathrm{b}}$ & $6.98 \pm 1.27^{\mathrm{b}}$ & $6.78 \pm 1.26$ \\
\hline
\end{tabular}

Notes: ${ }^{a} P<0.05$ versus both nonrecent $H G$ and never $H G$ groups; ${ }^{b} P<0.05$ versus never HG group only.

Abbreviations: $\mathrm{HbA}_{\mathrm{lc}}$, glycated hemoglobin; HG, hypoglycemia; SD, standard deviation.

of those in the recent hypoglycemia group had low $\mathrm{HbA}_{1 \mathrm{c}}$ (50.0\%) compared with the nonrecent hypoglycemia group (55.2\%, $P<0.05$ ), both of which were significantly lower than the never hypoglycemia (64.3\%) group ( $P<0.05$ for both). The relationship between hypoglycemia and the percentage of participants with slightly elevated $\mathrm{HbA}_{1 \mathrm{c}}$ was similar to that of the total population.

Conversely, the percentage of participants experiencing hypoglycemia was examined based on $\mathrm{HbA}_{1 \mathrm{c}}$ group (Table 5). A significantly lower proportion of participants in the low $\mathrm{HbA}_{1 \mathrm{c}}$ group reported recent hypoglycemia (29.3\%) compared with both the slightly elevated $\mathrm{HbA}_{1 \mathrm{c}}(39.2 \%)$ and elevated $\mathrm{HbA}_{1 \mathrm{c}}(40.2 \%)$ groups ( $P<0.05$ for both). This corresponded to a significantly higher proportion of participants reporting never hypoglycemia (45.0\%) compared with the slightly elevated $\mathrm{HbA}_{1 \mathrm{c}}(33.1 \%)$ and elevated $\mathrm{HbA}_{1 \mathrm{c}}(32.6 \%)$ groups ( $P<0.05$ for both). In participants who reported not knowing their $\mathrm{HbA}_{1 \mathrm{c}}$ levels $(\mathrm{n}=2,019)$, the percentage that reported experiencing a recent hypoglycemia $(22.6 \%)$ was significantly lower than for the low, slightly elevated, and elevated $\mathrm{HbA}_{1 \mathrm{c}}$ groups $(P<0.05$ for all). The percentage of participants who did not know their $\mathrm{HbA}_{1 \mathrm{c}}$ levels and reported never experiencing hypoglycemia (51.7\%) was significantly higher than in the low, slightly elevated, and elevated $\mathrm{HbA}_{1 \mathrm{c}}$ groups $(P<0.05$ for all).
The never hypoglycemia group had the lowest use of insulin (17.0\%) compared with the nonrecent hypoglycemia (32.4\%) and recent hypoglycemia ( $46 \%$ ) groups ( $P<0.05$ in both). The never hypoglycemia group also had the lowest use of sulfonylurea and glucagon-like peptide-1 agonists (Table 3).

The mean BMI was $33.3 \mathrm{~kg} / \mathrm{m}^{2}$ in the never hypoglycemia group and $34.0 \mathrm{~kg} / \mathrm{m}^{2}$ in both the recent and nonrecent hypoglycemia groups (Table 3 ). More than $60 \%$ of participants were overweight or obese. Diabetes disease burden was higher in participants with hypoglycemia. The mean CCI score was highest in those with recent hypoglycemia (1.88) compared with those with nonrecent hypoglycemia (1.72; $P=0.05$ versus recent hypoglycemia) and never hypoglycemia $(1.52 ; P<0.05$ versus both the recent hypoglycemia and nonrecent hypoglycemia groups).

Of all participants taking antihyperglycemic agents, $52 \%$ reported medium to low adherence with their medications, a quarter of whom had low adherence. The recent hypoglycemia group had the highest proportion of medium or low adherence followed by the nonrecent hypoglycemia and never hypoglycemia groups (Table 6).

Hypoglycemia had significant impact on participants' lives. A larger proportion of participants in the recent hypoglycemia and nonrecent hypoglycemia groups reported moderately to extreme interference with social activities compared with the never hypoglycemia group (Table 7). Work productivity was also impacted. Those with recent hypoglycemia had significantly higher absenteeism (7.6\%), presenteeism $(21.3 \%)$, and total work productivity impairment $(25.5 \%)$ due to health compared with those with nonrecent hypoglycemia $(4.4 \%, 15.1 \%$, and $18.0 \%$, respectively; $P<0.05$ for all comparisons) or never hypoglycemia (3.5\%, $14.0 \%$, and $16.3 \%$, respectively; $P<0.05$ for all comparisons; Figure 2). Overall, recent hypoglycemia episodes contributed to lower HRQoL. General health summary scores across all domains of the SF-36, physical and mental, were significantly lower in participants with recent hypoglycemia compared with those with nonrecent hypoglycemia or never hypoglycemia ( $P<0.05$ for all comparisons; Figure 3$)$.

Table 5 Percentage of participants reporting hypoglycemia by $\mathrm{HbA}_{\mathrm{lc}}$ level

\begin{tabular}{|c|c|c|c|c|c|}
\hline n (\%) & $\begin{array}{l}\text { Low } \\
(<7.0 \%) \\
n=2,073\end{array}$ & $\begin{array}{l}\text { Slightly elevated } \\
(\geq 7 \% \text { to } \leq 8.5 \%) \\
n=1,269\end{array}$ & $\begin{array}{l}\text { Elevated } \\
(>8.5 \% \text { to } \leq \mathrm{II} .0 \%) \\
\mathrm{n}=\mathbf{2 3 9}\end{array}$ & $\begin{array}{l}\text { Seriously elevated } \\
(>11.0 \%) \\
n=52\end{array}$ & $\begin{array}{l}\text { Do not know } \\
n=2,019\end{array}$ \\
\hline Recent HG & $607(29.3)^{\mathrm{a}}$ & $498(39.2)$ & $96(40.2)$ & $14(26.9)$ & $456(22.6)^{b}$ \\
\hline Nonrecent HG & $533(25.7)$ & $351(27.7)$ & $65(27.2)$ & 17 (32.7) & $520(25.8)$ \\
\hline Never HG & $933(45.0)^{\mathrm{a}}$ & $420(33.1)$ & $78(32.6)$ & $21(40.4)$ & $\mathrm{I}, 043(5 \mathrm{I} .7)^{\mathrm{b}}$ \\
\hline
\end{tabular}

Notes: ${ }^{a} P<0.05$ versus the slightly elevated, elevated, and do not know groups; ${ }^{b} P<0.05$ versus the low, slightly elevated, and elevated groups. Abbreviations: $\mathrm{HbA}_{1 \mathrm{c}}$, glycated hemoglobin; $\mathrm{HG}$, hypoglycemia. 
Table 6 Morisky Medication Adherence Scale scores in participants taking antihyperglycemic agents

\begin{tabular}{llll}
\hline $\begin{array}{l}\text { Adherence } \\
\text { score }\end{array}$ & $\begin{array}{l}\text { Recent HG } \\
(\mathbf{n}=1, \mathbf{6 8 8})\end{array}$ & $\begin{array}{l}\text { Nonrecent HG } \\
(\mathbf{n}=1,5 \mathrm{I} \mathbf{6})\end{array}$ & $\begin{array}{l}\text { Never HG } \\
(\mathbf{n}=\mathbf{2 , 5 5 2})\end{array}$ \\
\hline High $(7)$ & $660(39.1 \%)^{\mathrm{a}}$ & $69 \mathrm{I}(45.6 \%)^{\mathrm{b}}$ & $\mathrm{I}, 4 \mathrm{II}(55.3 \%)$ \\
Medium (5-6) & $733(43.4 \%)^{\mathrm{b}}$ & $607(40.0 \%)^{\mathrm{b}}$ & $901(35.3 \%)$ \\
Low $(<5)$ & $295(17.5 \%)^{\mathrm{a}}$ & $218(14.4 \%)^{\mathrm{b}}$ & $240(9.4 \%)$ \\
\hline
\end{tabular}

Notes: ${ }^{\mathrm{P}}<0.05$ versus both nonrecent $\mathrm{HG}$ and never $\mathrm{HG}$ groups; ${ }^{\mathrm{b}} \mathrm{P}<0.05$ versus never $\mathrm{HG}$ group only.

Abbreviation: HG, hypoglycemia.

\section{Discussion}

Studies have shown that glycemic control deteriorates progressively over time, necessitating increased use of insulin therapy. Although this approach may lessen the deterioration, it may come at the expense of significant weight gain and hypoglycemia. ${ }^{22}$ Despite newer antihyperglycemic agent treatment options, such as the dipeptidylpeptidase-4 inhibitors and glucagon-like peptide-1 agonists, a large proportion of people with T2DM still report experiencing hypoglycemia. To our knowledge, this is the first large-scale study to characterize the impact of hypoglycemia on diabetes burden, HRQoL, and work productivity from the patient perspective in a single analysis. The results of this study offer insight into the demographics and clinical characteristics of survey participants who experienced hypoglycemia (recent or nonrecent) or never experienced hypoglycemia. In addition, the results show that hypoglycemia negatively impacts social function, overall HRQoL, work productivity, and medication adherence.

The results suggest that adults with $\mathrm{T} 2 \mathrm{DM}$ who experience hypoglycemia tend to be younger, be more aware of their $\mathrm{HbA}_{1 \mathrm{c}}$ levels and have higher $\mathrm{HbA}_{1 \mathrm{c}}$ levels, have higher BMIs, have higher CCI scores, be treated with insulin, sulfonylureas, or glucagon-like peptide-1 agonists, and be less adherent to their antihyperglycemic agents compared with those who never experience hypoglycemia. The impact appears even

Table 7 Extent of interference with social activities in the previous 4 weeks in participants taking antihyperglycemic agents by $\mathrm{HG}$ experience

\begin{tabular}{llll}
\hline Frequency & $\begin{array}{l}\text { Recent HG } \\
(\mathbf{n}=\mathbf{I}, \mathbf{6 8 8})\end{array}$ & $\begin{array}{l}\text { Nonrecent HG } \\
(\mathbf{n}=\mathrm{I}, \mathbf{5} \mathrm{I6})\end{array}$ & $\begin{array}{l}\text { Never HG } \\
(\mathbf{n}=\mathbf{2 , 5 5 2})\end{array}$ \\
\hline Not at all & $615(36.4 \%)^{\mathrm{a}}$ & $69 \mathrm{I}(45.6 \%)$ & $\mathrm{I}, 437(56.3 \%)$ \\
Slightly & $433(25.7 \%)^{\mathrm{b}}$ & $349(23.0 \%)$ & $537(21.0 \%)$ \\
Moderately & $319(18.9 \%)^{\mathrm{b}}$ & $255(16.8 \%)^{\mathrm{b}}$ & $342(13.4 \%)$ \\
Quite a bit & $235(13.9 \%)^{\mathrm{a}}$ & $166(11.0 \%)^{\mathrm{b}}$ & $176(6.9 \%)$ \\
Extremely & $86(5.1 \%)^{\mathrm{a}}$ & $55(3.6 \%)^{\mathrm{b}}$ & $60(2.4 \%)$ \\
\hline
\end{tabular}

Notes: ${ }^{\mathrm{a}}<<0.05$ versus both nonrecent $\mathrm{HG}$ and never HG groups; ${ }^{\mathrm{b}} \mathrm{P}<0.05$ versus never HG group only.

Abbreviation: $\mathrm{HG}$, hypoglycemia. greater in those experiencing recent hypoglycemia. Although we did not expect the never hypoglycemia group to have an older mean age than the nonrecent hypoglycemia or recent hypoglycemia groups, and we really do not know the reason behind these findings, we can speculate that older patients may be more prone to recall bias and other limitations inherent with surveys. Also, we may expect the risks of hypoglycemia to increase with advancing age, but the recognition of hypoglycemia signs may decrease.

The association of hypoglycemia with poor glycemic control is consistent with the notion that the fear of hypoglycemia leads to maintenance of higher glycemic levels, although there is little evidence in the literature to support this. ${ }^{5,8}$ The results of this study would add support, as almost twice the percentage of those with recent hypoglycemia (29.5\%) had slightly elevated $\mathrm{HbA}_{1 \mathrm{c}}$ levels $(7.0 \%-8.5 \%)$ compared with those who never had hypoglycemia $(16.5 \%)$. The association between hypoglycemia and poor medication adherence is consistent with other observations in the literature. A database analysis using the 2006-2008 NHWS found a significant association between the number of tolerability issues (hypoglycemia, constipation/diarrhea, headaches, weight gain, and water retention) and medication nonadherence in participants with T2DM. Each additional tolerability issue was associated with a $28 \%$ greater likelihood of medication nonadherence. ${ }^{23} \mathrm{~A}$ European study in people with T2DM that added a sulfonylurea or a thiazolidinedione to ongoing metformin therapy reported that those with hypoglycemia were significantly more likely to report barriers to adherence. ${ }^{24}$ A study drawing on a large administrative database of managed care plans (Impact database; Ingenix) showed that in people with T2DM on one or more oral antihyperglycemic agents, having one or more hypoglycemic events within a 6-month interval was significantly associated with treatment discontinuation over this period and the subsequent 6-month interval. ${ }^{25}$ There has been an association observed between better medication adherence and better glycemic control in people with T2DM. ${ }^{20,26}$ The results of this study show that hypoglycemia may be a significant factor in medication adherence and glycemic control, given that both were poorer in those having nonrecent hypoglycemia compared with those never having hypoglycemia, and were even worse in those with recent hypoglycemia compared with those with nonrecent hypoglycemia.

Poor medication adherence and glycemic control in people with T2DM with hypoglycemia may be a result of the additional burden caused by fear of hypoglycemia and the need to manage it. Diabetes is a chronic disease that involves 


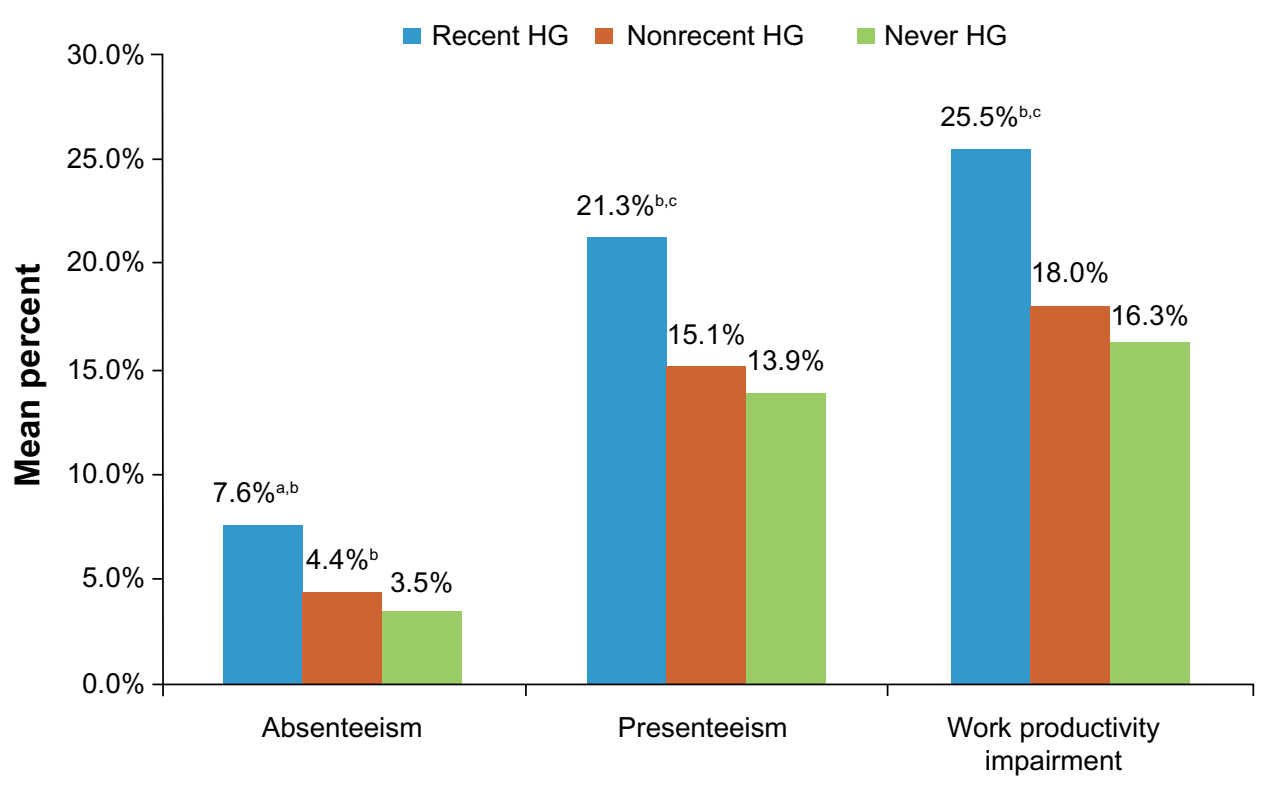

Figure 2 Work productivity in participants taking antihyperglycemic agents.

Notes: Absenteeism refers to mean percentage of work time missed due to health (currently employed full-time people); presenteeism refers to mean percentage impairment while working due to health (currently employed full-time people); work productivity impairment refers to mean overall work impairment due to health. a $<<0.05$ versus nonrecent $H G$. ${ }^{b} P<0.00$ I versus never $H G$. ${ }^{c} P=0.001$ versus nonrecent $H G$.

Abbreviation: HG, hypoglycemia.

constant monitoring of behaviors and habits (eg, eating, social activities, exercise) in order to maintain proper glycemic control, and hypoglycemia appears to add to these burdens. Study participants who had a previous hypoglycemia reported feeling more "hassled" about taking their antihyperglycemic agents compared with participants who had never had hypoglycemia (data not reported). Increased interference with social activities, missed work, and work impairment were also reported in those with hypoglycemia and more so in those with recent hypoglycemia. Thus, it is no surprise that overall HRQoL decreased in those with nonrecent hypoglycemia and decreased further in those with recent hypoglycemia.

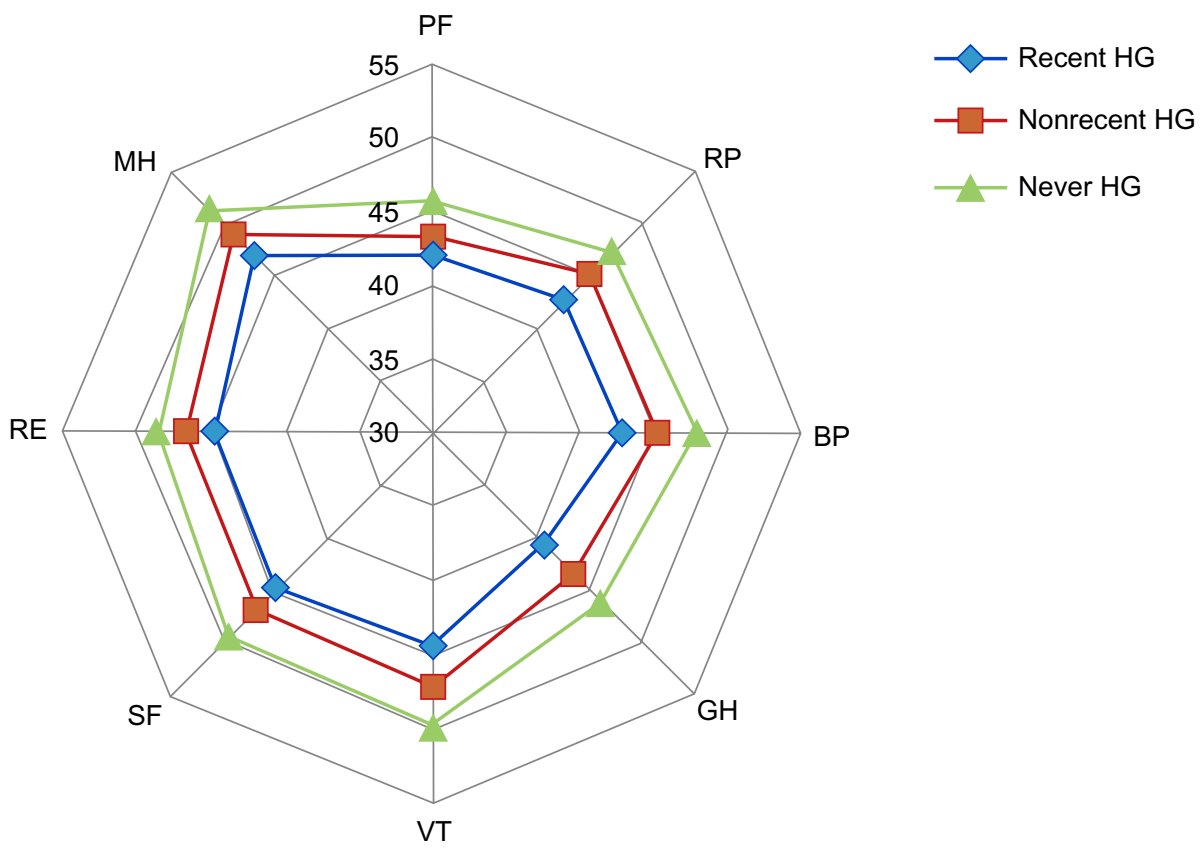

Figure 3 General health summary scores (Short Form-36) in participants taking antihyperglycemic agents who know their hypoglycemic status.

Abbreviations: PF, physical functioning; RP, role-physical; BP, body pain; GH, general health; VT, vitality; SF, social functioning; RE, role-emotional; MH, mental health; HG, hypoglycemia. 
Hypoglycemia is associated with significant morbidity and mortality, which further adds to the burden for people with T2DM. ${ }^{27}$ In this study, mean CCI scores were highest in participants with recent hypoglycemia, followed by those who had nonrecent hypoglycemia and those who never had hypoglycemia. The higher disease burden and risk of mortality in those with hypoglycemia is consistent with observations that hypoglycemia may increase morbidity and mortality in people with T2DM. In a post-hoc analysis of the ADVANCE (Action in Diabetes and Vascular Disease: Preterax and Diamicron Modified-Release Control Evaluation) trial, severe hypoglycemia was associated with significant increases in the risks of major microvascular and macrovascular events and deaths. ${ }^{28}$ In the ACCORD (Action to Control Cardiovascular Risk in Diabetes) and ADVANCE trials, patients with a history of severe hypoglycemia events had approximately a 1.4-fold to 3-fold higher risk of mortality, with one-third to one-half of all deaths being cardiovascular in nature. However, it is not known if severe hypoglycemia contributes to adverse outcomes or if it is a marker of vulnerability to these events. ${ }^{28,29}$

Because this analysis is based on a patient survey, there are caveats to keep in mind when interpreting its findings. The data collected are subject to recall bias, missing values, and variability in the interpretation of questions. Certain characteristics such as BMI and CCI were based on patient self-reported information and, thus, may be susceptible to bias. In addition, due to limitations regarding how the data were collected and the descriptive nature of the study, there were no adjustments for factors such as severity of hypoglycemia and unknown $\mathrm{HbA}_{1 \mathrm{c}}$ levels. The descriptive nature of the study also precludes any definitive conclusions regarding causality being made in any of the observed relationships. Furthermore, the survey depended on participant interpretation and reporting of hypoglycemia episodes as opposed to biochemical documentation with a glucose reading. Finally, the survey was Internet-based, and so may not be fully representative of the entire population with T2DM given that it only includes participants who have computer access and a degree of computer literacy. Thus, although certain demographic characteristics (eg, sex, age, region) approximate the US census population, this survey sample may not be completely generalizable to the entire population with T2DM.

\section{Conclusion}

The results of this study highlight the significant burden of hypoglycemia from a patient perspective and its impact on
HRQoL, work productivity, and medication adherence. The causes of hypoglycemia are likely multifactorial. Patient education regarding hypoglycemia early in the disease course may be helpful, since the fear of future hypoglycemia events may result in poor medication adherence and glycemic control that could lead to the development of long-term T2DMassociated complications. Another important consideration is the selection of antihyperglycemic treatment, given that certain classes of medications are associated with higher risks of hypoglycemia. This analysis focused on patients' perspectives of hypoglycemia, but it is also important to consider the impact of hypoglycemia in other areas. From the perspectives of the health care provider, payer, and employer, increasing attention towards hypoglycemia in people with T2DM may increase work productivity and decrease health care utilization. These results support the need for multi-modal approaches, including careful selection of medication regimens, to minimize the risk and burden of hypoglycemia.

\section{Acknowledgments}

The authors would like to thank Kenneth Chiang and ECIR Medical Communications for writing and editorial support.

\section{Disclosure}

JMSL, RAB, and MFTR are employees of Janssen Pharmaceuticals, Inc. KA is an employee of Kantar Health. DEM reports no conflicts of interest.

\section{References}

1. International Diabetes Foundation (IDF). Risk Factors for Diabetes; 2005 Available from: http://www.cvd.idf.org/Diabetes/Risk_Factors_for_ Diabetes/index.html. Accessed March 14, 2013.

2. Inzucchi SE, Bergenstal RM, Buse JB, et al. Management of hyperglycemia in type 2 diabetes: a patient-centered approach. Position statement of the American Diabetes Association (ADA) and the European Association for the Study of Diabetes (EASD). Diabetes Care. 2012;35:1364-1379.

3. Rodbard HW, Jellinger PS, Davidson JA, et al. Statement by an American Association of Clinical Endocrinologists/American College of Endocrinology consensus panel on type 2 diabetes mellitus: an algorithm for glycemic control. Endocr Pract. 2009;15:540-559.

4. Barendse S, Singh H, Frier BM, Speight J. The impact of hypoglycaemia on quality of life and related patient-reported outcomes in type 2 diabetes: a narrative review. Diabet Med. 2012;29:293-302.

5. Barnett AH, Cradock S, Fisher M, Hall G, Hughes E, Middleton A. Key considerations around the risks and consequences of hypoglycaemia in people with type 2 diabetes. Int J Clin Pract. 2010;64:1121-1129.

6. Weitzman ER, Kelemen S, Quinn M, Eggleston EM, Mandi KD. Participatory surveillance of hypoglycemia and harms in an online social network. JAMA Intern Med. 2013;173:345-351.

7. Moghissi E, Ismail-Beigi F, Devine RC. Hypoglycemia: minimizing its impact in type 2 diabetes. Endocr Pract. 2013;19:526-535. 
8. Cryer PE. The barrier of hypoglycemia in diabetes. Diabetes. 2008;57: 3169-3176.

9. Amiel SA, Dixon T, Mann R, Jameson K. Hypoglycaemia in type 2 diabetes. Diabet Med. 2008;25:245-254.

10. DiBonaventura MD, Wagner JS, Yuan Y, L'Italien G, Langley P, Ray Kim W. Humanistic and economic impacts of hepatitis $\mathrm{C}$ infection in the United States. J Med Econ. 2010;13:709-718.

11. Finkelstein EA, Allaire BT, DiBonaventura MD, Burgess SM. Direct and indirect costs and potential cost savings of laparoscopic adjustable gastric banding among obese patients with diabetes. J Occup Environ Med. 2011;53:1025-1029.

12. Bolge SC, Doan JF, Kannan H, Baran RW. Association of insomnia with quality of life, work productivity, and activity impairment. Qual Life Res. 2009;18:415-422.

13. Centers for Disease Control and Prevention. Number (in millions) of civilian, noninstitutionalized adults with diagnosed diabetes, United States, 1980-2011. March 2, 2013. Available from: http://www.cdc.gov/ diabetes/statistics/prev/national/figadults.htm. Accessed November 6 , 2013.

14. Monami M, Lambertucci L, Lamanna C, et al. Are comorbidity indices useful in predicting all-cause mortality in type 2 diabetic patients? Comparison between Charlson index and disease count. Aging Clin Exp Res. 2007;19:492-496.

15. McEwen LN, Karter AJ, Waitzfelder BE, et al. Predictors of mortality over 8 years in type 2 diabetic patients: Translating Research Into Action for Diabetes (TRIAD). Diabetes Care. 2012;35:1301-1309.

16. Morisky DE, Ang A, Krousel-Wood M, Ward HJ. Predictive validity of a medication adherence measure in an outpatient setting. $J$ Clin Hypertens (Greenwich). 2008;10:348-354.

17. Al-Qazaz HK, Hassali MA, Shafie AA, Sulaiman SA, Sundram S, Morisky DE. The eight-item Morisky Medication Adherence Scale MMAS: translation and validation of the Malaysian version. Diabetes Res Clin Pract. 2010;90:216-221.

18. Krapek K, King K, Warren SS, et al. Medication adherence and associated hemoglobin $\mathrm{A}_{1 \mathrm{c}}$ in type 2 diabetes. Ann Pharmacother. 2004;38: 1357-1362.

19. Jamous RM, Sweileh WM, Abu-Taha AS, Sawalha AF, Zyoud SH, Morisky DE. Adherence and satisfaction with oral hypoglycemic medications: a pilot study in Palestine. Int J Clin Pharm. 2011;33: 942-948.
20. Aikens JE, Piette JD. Longitudinal association between medication adherence and glycaemic control in type 2 diabetes. Diabet Med. 2013;30:338-344

21. Ware JE, Snow KK, Kosinski M, Gandek B. SF-36 $6^{\circledR}$ Health Survey Manual and Interpretation Guide. Boston, MA: New England Medical Center, The Health Institute, 1993.

22. Best JD, Drury PL, Davis TME, et al. Glycemic control over 5 years in 4,900 people with type 2 diabetes. Diabetes Care. 2012;35: 1165-1170.

23. Pollack MF, Purayidathil FW, Bolge SC, Williams SA. Patient-reported tolerability issues with oral antidiabetic agents: associations with adherence; treatment satisfaction and health-related quality of life. Diabetes Res Clin Pract. 2010;87:204-210.

24. Alvarez Guisasola F, Tofe Povedano S, Krishnarajah G, Lyu R, Mavros P, Yin D. Hypoglycaemic symptoms, treatment satisfaction, adherence and their associations with glycaemic control in patients with type 2 diabetes mellitus: findings from the Real-Life Effectiveness and Care Patterns of Diabetes Management (RECAP-DM) Study. Diabetes Obes Metab. 2008;10 Suppl 1:25-32.

25. Bron M, Marynchenko M, Yang H, Yu AP, Wu EQ. Hypoglycemia, treatment discontinuation, and costs in patients with type 2 diabetes mellitus on oral antidiabetic drugs. Postgrad Med. 2012;124: 124-132.

26. Asche C, LeFleur J, Conner C. A review of diabetes treatment adherence and the association with clinical and economic outcomes. Clin Ther. 2011;33:74-109.

27. Noh RM, Graveling AJ, Frier BM. Medically minimizing the impact of hypoglycaemia in type 2 diabetes: a review. Expert Opin Pharmacother. 2011;12:2161-2175.

28. Zoungas S, Patel A, Chalmers J, et al. Severe hypoglycemia and risks of vascular events and death. N Engl J Med. 2010;363:1410-1418.

29. Bonds DE, Miller ME, Bergenstal RM, et al. The association between symptomatic, severe hypoglycaemia and mortality in type 2 diabetes: retrospective epidemiological analysis of the ACCORD study. BMJ. 2010;340:b4909.
Patient Preference and Adherence

\section{Publish your work in this journal}

Patient Preference and Adherence is an international, peer-reviewed, open access journal focusing on the growing importance of patient preference and adherence throughout the therapeutic continuum. Patient satisfaction, acceptability, quality of life, compliance, persistence and their role in developing new therapeutic modalities and compounds to

\section{Dovepress}

optimize clinical outcomes for existing disease states are major areas of interest. This journal has been accepted for indexing on PubMed Central. The manuscript management system is completely online and includes a very quick and fair peer-review system. Visit http://www.dovepress.com/ testimonials.php to read real quotes from published authors. 